\title{
Seismic Reliability and Risk Assessment of Structures Based on Fragility Analysis - A Review
}

\author{
M. G. Sfahani *, Hong Guan, and Yew-Chaye Loo \\ Griffith School of Engineering, Griffith University Gold Coast Campus, \\ Queensland 4222, Australia
}

\begin{abstract}
A practical approach to explain the consequences of seismic hazards for society and decision making organisations is predicting the seismic risk. In this regard, the Probabilistic Seismic Hazard Analysis (PSHA) is used extensively to investigate the probability of different seismic hazard levels at a geographical location. In addition, a further advancement is the introduction of Probabilistic Seismic Demand Analysis (PSDA) method because it provides a new insight into the Performance-Based Earthquake Engineering (PBEE) by evaluating the seismic risk specifically for a structure. To evaluate this seismic risk, the probability that the structural seismic demands may exceed a specific value is calculated under different ground motion intensities through a probabilistic approach. This approach is called the fragility analysis. This paper provides a review of recent research advancements in seismic fragility analysis. Different methods and related solutions which can be used for the fragility analysis are discussed. In addition, uncertainty quantification, as a significant feature in fragility analysis, is described and the important parameters which may influence the seismic fragility of a structure are explained. Finally, the authors offer their recommendations for improving the fragility analysis for further studies in the future.
\end{abstract}

Keywords: Fragility analysis; Seismic hazard: Seismic demand; Uncertainty quantification; Performance limit-states

\footnotetext{
*Corresponding author; Email address: m.ghalamisfahani@griffith.edu.au Fax: + 617-55528065; Tel: $+617-55527608$.
} 


\section{INTRODUCTION}

\subsection{General Remarks}

Natural hazards have always had undesirable influences on infrastructure, human life, economy and communities. Recent advances in computational science and technology have resulted in higher safety levels against natural hazards for the benefit of human societies. However, earthquakes remain one of the most unpredictable natural hazards due to the randomness of the return period and the shaking intensity. Initial academic and scientific attempts for mitigating fatalities and financial losses of earthquakes started in the early 1900s and have resulted in several structural seismic provisions and building standards. Since this achievement has been accomplished only in the past few decades, a large number of structures remained which are unable to satisfy the requirements of the well-accepted seismic standards. Consequently, while the new earthquake-resistant structures are designed to have an appropriate balance of stiffness and ductility, the existing aged structures are more susceptible to earthquakes. Therefore, seismic performance assessment of the existing structures is a key element in the process of achieving the safety against seismic hazard.

\subsection{Code-Based Seismic Performance Assessment}

Primary code-based guidelines for seismic performance assessment and rehabilitation of structures were presented by FEMA 273 (1997) and FEMA 274 (1997), and later by FEMA 356 (2000). These guidelines were the culmination of a long-term project, sponsored by the Federal Emergency Management Agency (FEMA) of the United States, to determine the seismic performance assessment of structures. They were developed by a group of specialists in earthquake engineering and seismic rehabilitation, from the Applied Technology Council (ATC), the National Earthquake Hazards Reduction Program (NEHRP), and a consortium of universities for research in earthquake engineering (CUREE). Unlike the prescriptive 
procedure of the traditional building codes for design of new structures, four different performance levels are proposed in these guidelines (“operational”, “immediate occupancy”, "life safety", and "collapse prevention") in which each represents a specific seismic damage level (“slight”, “moderate”, “extensive”, and "complete”, respectively). Then, the combination of the seismic damage level and seismic hazard level indicates the likelihood of exceeding a performance level, which is a beneficial tool for determining the rehabilitation strategy. Nevertheless, in 2007, ASCE 41-06 (2007) was introduced as the only standard for seismic performance assessment of structures and it has since superseded other guidelines. ASCE 41-06 provides two rehabilitation methods: a simplified method which is aimed for small, regular, and simple structures and a systematic method for predicting performance of complex structures and minimising the cost of rehabilitation. Moreover, four different structural analysis methods (linear static, nonlinear static, linear dynamic, and nonlinear dynamic), with related acceptance criteria, were defined by ASCE 41-06 in which, when the complexity of a structure increases, a nonlinear and/or dynamic analysis is required.

ASCE 41-06 represents the current standard of practice to achieve an objective structural performance level against seismic loads, however, compliance to this standard does guarantee the achievement of the desired performance. Earthquakes are accompanied by different sources of uncertainty, such as ambiguities in location (epicentre), and magnitude of the ground motions. The uncertainty increases in the structural engineering phase by encompassing the structural modelling uncertainties as well as the randomness of structural seismic responses. However, although compliance to ASCE 41-06 suggests the use of seismic hazard maps to find the maximum considered earthquake for structural analyses, there is no provision to investigate the variation of seismic responses when multiple seismic events are considered. Under these circumstances, ASCE 41-06 seems to discourage, or even prohibit, the use of engineering judgment and decision making by its prescriptive procedure (Searer et 
al. 2008). As a consequence, even inexperienced structural engineers are then encouraged to carry out performance-based seismic evaluation and design by using ASCE 41-06 which results in inappropriate engineering analysis, overestimation, dispensable strengthening of structures, and additional costs (Paret et al. 2011).

\subsection{Current Research}

A probabilistic earthquake engineering framework is an alternative for seismic performance assessment of the structures that incorporates the details of seismic analysis or design assumptions. Using such a framework, the seismic damage vulnerability of a structure can be represented in the form of a series of fragility curves which allows a decision maker to adopt a rehabilitation level according to his/her engineering judgment. Recently, a performancebased earthquake engineering (PBEE) framework has been developed by the Pacific Earthquake Engineering Research (PEER) Centre and other research organisations (Cornell and Krawinkler 2000; Günay and Mosalam 2013). This framework estimates the probabilistic seismic performance of structures in terms of system-level decision variables (repair cost, casualties, and loss of functionality). The framework consists of four stages: (a) hazard analysis (intensity of the ground motions threatening the structure); (b) structural analysis (input seismic loads and output structural responses); (c) damage analysis (current condition and after-event performance of the structure); and (d) loss estimation (dollars, deaths, and downtime). In terms of the first stage of this framework, hazard analysis, the mean annual frequency (MAF) of seismic hazard is estimated for a range of ground motion intensities with different magnitudes and epicentral distances. In fact, this stage is established on the Probabilistic Seismic Hazard Analysis (PSHA) as proposed by Cornell (1968). The hazard maps (or curves), which are now provided by seismic codes, in the form of Peak Ground Motion (PGA) or Spectral acceleration (Sa), rely heavily on PSHA which, itself, is composed 
of four steps: (a) identifying earthquake sources and magnitudes; (b) identifying earthquake distances; (c) predicting ground motion intensities; and (d) combining information of the first three steps for achieving the hazard curves. Earlier development of PSHA was reviewed and summarised by McGuire (2008).

In regard to the second stage of the abovementioned framework, structural analysis, advances in computer sciences and numerical modelling during past decades have provided the possibility of performing complex structural analysis. This scientific advancement has been particularly accelerated by the introduction of Incremental Dynamic Analysis (IDA) for investigating the nonlinear seismic responses of structures under different shaking levels of a same seismic event (Vamvatsikos and Cornell 2002). Nevertheless, ongoing earthquake risk studies mainly contribute to the third stage of the framework, which attempts to determine the risk of seismic structural damage levels instead of the risk of seismic hazard levels (first stage), in order to present an overview of the seismic performance of the structure (Bazzurro 1998; Shome 1999). In these studies, a structural performance level is demonstrated by specifying a seismic damage level calling the limit-state (Bazzurro 1998). As a consequence, it is possible to evaluate the MAF of exceeding the limit-states apart from the MAF of the seismic hazard levels. This procedure is referred to as the Probabilistic Seismic Demand Analysis (PSDA) (Bazzurro, 1998; Shome 1999; Carballo and Cornell 2000; Luco 2002). PSDA requires structure-specific nonlinear analysis with a relatively small set of recorded accelerograms for seismic hazard analysis, and it provides the next stage of development for seismic assessment that considers the uncertainties in nonlinear response and capacity (Shome 1999). Indeed, PSDA has become the basis of extensive research in earthquake engineering for structural damage analysis. The most significant result of PSDA is a set of curves which illustrate the likelihood of exceeding a structural performance level, caused by different ground shaking intensities, namely the fragility curve. Recently, during the 
SAC/FEMA* project (Mahin et al. 2002), the procedure for developing seismic fragility curves of structures has been revised, and hence, a new insight was provided into the seismic risk analysis (Shome et al. 1998; Luco and Cornell 2000).

\subsection{Aims and Scope}

Although seismic fragility analysis has undergone continued development, efficient, practical and more accurate fragility curves are just at the initial stage of development. This paper presents a state-of-the-art review of seismic fragility analysis. In addition to the introduction (i.e. Section 1), this paper consists of six sections. In Section 2, conventional methods for developing fragility curves, as well as novel closed-form solutions for fragility function, are described. In Section 3, it is explained how the structural uncertainties are reflected in the fragility analysis. Also, the latest studies for performing hybrid fragility analysis, as well as the techniques for structural system reliability analysis, are reviewed. In Section 4 the importance of choosing a proper ground motion intensity in fragility analysis is highlighted and the defined characteristics for an optimal ground motion intensity are studied. Factors required to be considered for seismic record selection are discussed in the same section. Similar to Section 4, in Section 5 the significance of using an appropriate damage measure in earthquake engineering is emphasized. In this section, the current definition of structural performance during an earthquake is described and the importance of considering cumulative damage indices in seismic damage analysis is underlined. In Section 6 the flexibility of fragility analysis to include the joint impact of additional hazard loads (e.g. corrosion, soil liquefaction, snow load, hurricane, and flood) is considered.

\footnotetext{
* The SAC project for reduction of earthquake hazards in steel moment resisting frames (SMRF) in US involved three joint venture partners: the SEAOC (Structural Engineers Association of California), ATC, and CUREE.
} 


\section{FRAGILITY ANALYSIS}

Seismic fragility analysis was initially introduced and used for the purpose of risk and safety assessment of structural components and mechanical assemblies in nuclear power plants (Kennedy et al. 1980; Kaplan et al. 1983). The outcome of analysis depicts the seismic risk exposure in the form of a curve, namely fragility curve, which represents the probability of exceeding a structural performance level in response to increasing earthquake intensity. Figure 1 shows schematic fragility curves of building structures where fragility curves were plotted for different structural performance levels. In fragility analysis, the structural performance levels are represented in the form of seismic damage measures (DM), namely limit-states (LS). Consequently, each fragility curve demonstrates the probability of exceeding a LS in response to increasing earthquake intensity.

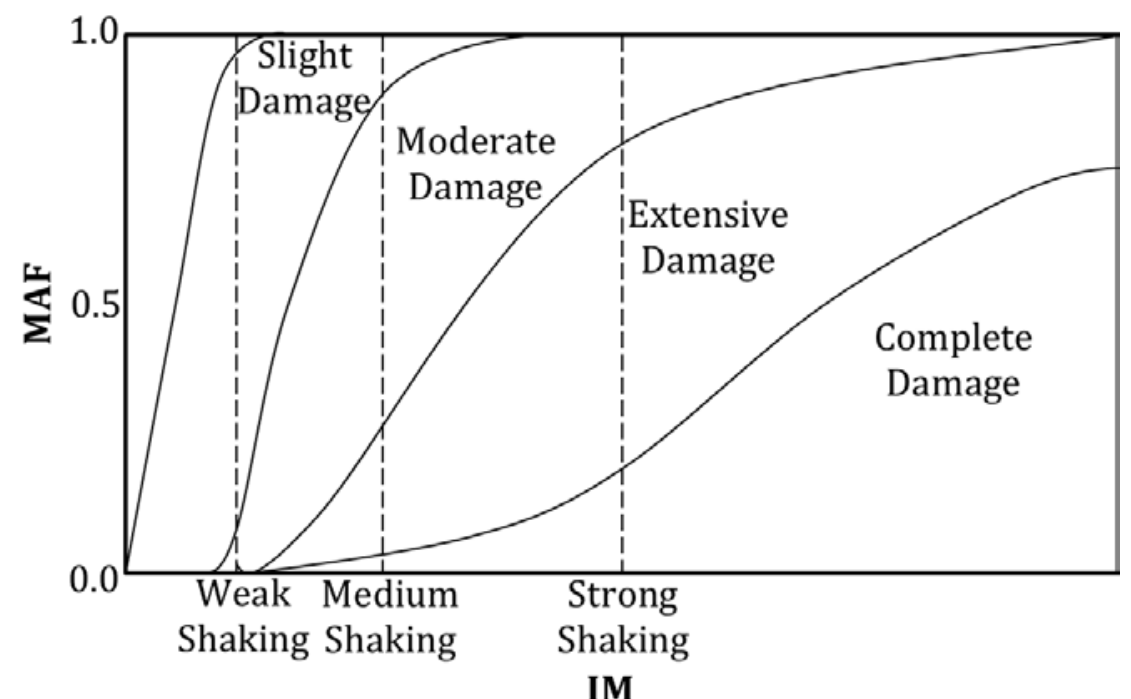

Figure 1. Example of building fragility curves for slight, moderate, extensive and complete damage

One advantage of calculating the fragility curves is that it permits the accomplishment of the last stage of PEER's PBEE framework, where the fragility curves are employed as the inputs for loss estimation. The most facilitating option for this purpose is the computer software 
“Hazus-MH” which contains models for estimating potential losses from earthquakes, floods and hurricanes (Hazus 2014). Hazus uses the Geographic Information Systems (GIS) based PSHA data standardized classified inventory of infrastructures and the calculated fragility curves to estimate the direct and indirect loss (Kircher et al. 2006). The outputs demonstrate the limits of identified high-risk locations due to a natural hazard (e.g. earthquake) in the form of graphical exposures which can be used for mitigation and recovery as well as preparedness and response (Kircher et al. 2006).

\subsection{Calculation of Fragility Curves}

Based on the sources of seismic data, fragility curves are generally divided into three main categories: empirical, judgmental and analytical (Rossetto and Elnashai 2003). Empirical fragility curves are developed based on the inspection and observation of the recorded structural damage from the post-earthquake surveys, and therefore are considered to be highly reliable. A procedure for developing fragility curves from empirical data has been proposed by Shinozuka et al. (2000). Typical empirical fragility curves can be found in the literature based on previous earthquakes, such as 1994 California (Basoz et al. 1999), 1995 Kobe (Karim and Yamazaki 2001), 2006 Indonesia (Khalfan 2013) and 2009 Italy (D’Ayala and Paganoni 2011), for bridges and masonry structures. Also, in the absence of real earthquake data, large scale shaking table tests have been used to generate empirical (experimental) fragility curves (Bothara et al. 2010; Banerjee and Shinozuka 2008a).

However, because of insufficient real earthquake data and costly experimental testing, the use of empirical fragility curves is infrequent. An alternative is to develop judgemental fragility curves in which the experts' opinions are requested and collected on the vulnerability of structural components to future earthquakes. Mosleh and Apostolakis (1986) have developed a probabilistic approach for approximating the probability distribution using experts' 
estimates. Porter et al. (2007) also suggested and produced a questionnaire for "soliciting expert judgment” on structural components fragility. Typical judgmental fragility curves for bridge components can be found in ATC-40 (1996). Employing the judgmental fragility curves is more beneficial because sufficient data can be collected, and it is less costly since expensive laboratory testing is not required. However, being purely established on expert opinion causes the uncertainty level of judgmental fragility curves to increase.

Analytical fragility curves are developed to avoid the costly experimental testing involved in empirical fragility curves and/or the uncertain data gathering on which the judgemental fragility curves are based. For this purpose, structures are modelled by computer software and analysed under simulated earthquake loads (Porter et al. 2001). The output seismic responses are then imported into the fragility function to derive the fragility curve. To formulate the analytical fragility function and obtain a solution for it, the probability of seismic demand (DM) exceeding a limit-state (LS) conditional on seismic intensity measure (IM) is expressed through the “Total Probability Theorem” (Benjamin and Cornell 1970), as

$$
\begin{aligned}
P[D M \geq L S]=\iint P[L S \mid D M] & \cdot d P[D M \mid I M] \cdot d P[I M] \\
& =\sum_{\text {all } x_{i}} P\left[D M \geq L S \mid I M=x_{i}\right] P\left[I M=x_{i}\right]
\end{aligned}
$$

In fact, the above equation denotes the two essential elements in seismic risk analysis: local seismicity $P\left[I M=x_{i}\right]$ and the probability of seismic damage and structural fragility $P\left[D M \geq L S \mid I M=x_{i}\right]$. The former is illustrated by seismic hazard curves (or maps) while the latter is demonstrated using fragility curves. To find a closed-form solution for the fragility function, it is required to establish a relation between the ground motion intensity (input) and the seismic demand (output). A power model, as follows, was proposed for this purpose (Cornell et al. 2002; Jalayer 2003),

$$
D M=a(I M)^{b}
$$


The most practical way to estimate the parameters, $a$ and $b$, is to conduct nonlinear dynamic analyses and plot DM versus IM followed by a regression analysis (Vamvatsikos and Cornell 2002; Jalayer 2003; Fragiadakis and Vamvatsikos 2010; Fajfar and Dolsek 2011). It is assumed that both the DM and IM are log-normally distributed with a dispersion value, in which $\beta_{D M \mid I M}$ represents the respective dispersion of median seismic demand over the range of ground motion intensities (Jalayer 2003). Consequently, the seismic fragility curve for a specific limit-state (LS) (the structural capacity (C) in this case) is obtained as

$$
P\left[D M \geq C \mid I M=x_{i}\right]=\Phi\left[\frac{\ln (D M)-\ln (C)}{\sqrt{\beta_{D M \mid I M}^{2}+\beta_{C}^{2}}}\right]
$$

In other word, the above equation denotes the probability of failure where $\beta_{C}$ is the dispersion value of median seismic capacity and $\Phi$ is the standard normal distribution. Some analytical fragility studies have been carried out, using the above closed-form solution, during the 1990s (Hwang and Hou 1994; Singhal and Kiremidjian 1996; Hwang and Jaw 1990). Nevertheless, as a part of the SAC/FEMA project a decision was made to also include probability of seismic hazard (seismicity) in the fragility function (Cornell et al. 2002; Mahin et al. 2002; Jalayer 2003). In regard to this, the seismic hazard is also approximated by a power model (Cornell 1968)

$$
H(I M)=P\left[I M \geq x_{i}\right] \cong k_{0} I M^{-k_{1}}=k_{0} \exp \left(-k_{1} \ln I M\right)
$$

where $k_{0}$ and $k_{1}$ are positive coefficients representing the intercept and slope of linear regression of seismic hazard in the logarithmic space, respectively. Subsequently, a fragility curve is obtained to demonstrate the annual probability of exceeding a limit-state as follows

$$
P[D M \geq L S]=H\left(I M^{L S}\right) \exp \left[\frac{1}{2} \frac{k_{1}^{2}}{b^{2}} \beta_{D M \mid I M}^{2}\right]
$$


and the probability of failure will take the following form

$$
P_{o F}=P[D M \geq C]=H\left(I M^{C}\right) \exp \left[\frac{1}{2} \frac{k_{1}^{2}}{b^{2}}\left(\beta_{D M \mid I M}^{2}+\beta_{C}^{2}\right)\right]
$$

where $I M^{L S}$ and $I M^{C}$ are the corresponding ground motion intensities to the limit-state (LS) and seismic capacity (C), based on the achieved power model (Eqn 2). If there was no dispersion $(\beta=0)$ then the probability of exceeding a limit state (or failure probability) could be determined by substituting these values into the seismic hazard approximation (Eqn 4). However, the dispersion values increase the probability since the value of the exponential phrase in Eqn 6, namely the "correction factor”, was reported to be typically between 1.5 and 3 (Cornell et al. 2002; Jalayer 2003).

\subsection{Error of Closed-Form Solution}

The above closed-form solution (Eqns 5 and 6) are the basis of the demand and capacity factor design (DCFD) method for performance-based seismic design and assessment in the SAC/FEMA project (Jalayer 2003). However, it is worth noting this solution employs simplifying assumptions which result in some errors. The dispersion value of the median seismic demand $\beta_{\mathrm{DM} \mid \mathrm{IM}}$, which is considered to be constant for the whole range of IM, is highly uncertain in the presence of an outlier. An outlier is an observation which deviates significantly from the rest of the distribution and arouses the suspicion that it follows a different distribution (Aslani and Miranda 2005). When a structure approaches the collapse stage, a small increment in the IM produces very large DM in which the result disregards the distribution of the remaining samples. To capture this variation, it was suggested to estimate DM at three different levels of ground motion intensity through a modified power model (Aslani and Miranda 2005), as follows

$$
D M=\alpha_{1} \alpha_{2}^{I M}(I M)^{\alpha_{3}}
$$




$$
\beta_{D M \mid I M}=\mu_{1}+\mu_{2}(I M)+\mu_{3}(I M)^{2}
$$

where $\alpha_{i}$ and $\mu_{i}$ are constants and are computed for the three pairs of IM-DM and IM $\beta_{\mathrm{DM} \mid \mathrm{IM}}$ at the corresponding IM level. Moreover, the approximation of the seismic hazard by a power-model (Eqn 4) indicates a linear distribution in log-log scale. As shown in Figure 2, this assumption is only suitable for small changes of IM while the closed-form solution is calculated by integration over the whole range of considered IM. This error can be reflected as a function of the curvature (second derivative) of seismic hazard curve in log-log space (Bradley and Dhakal 2008).

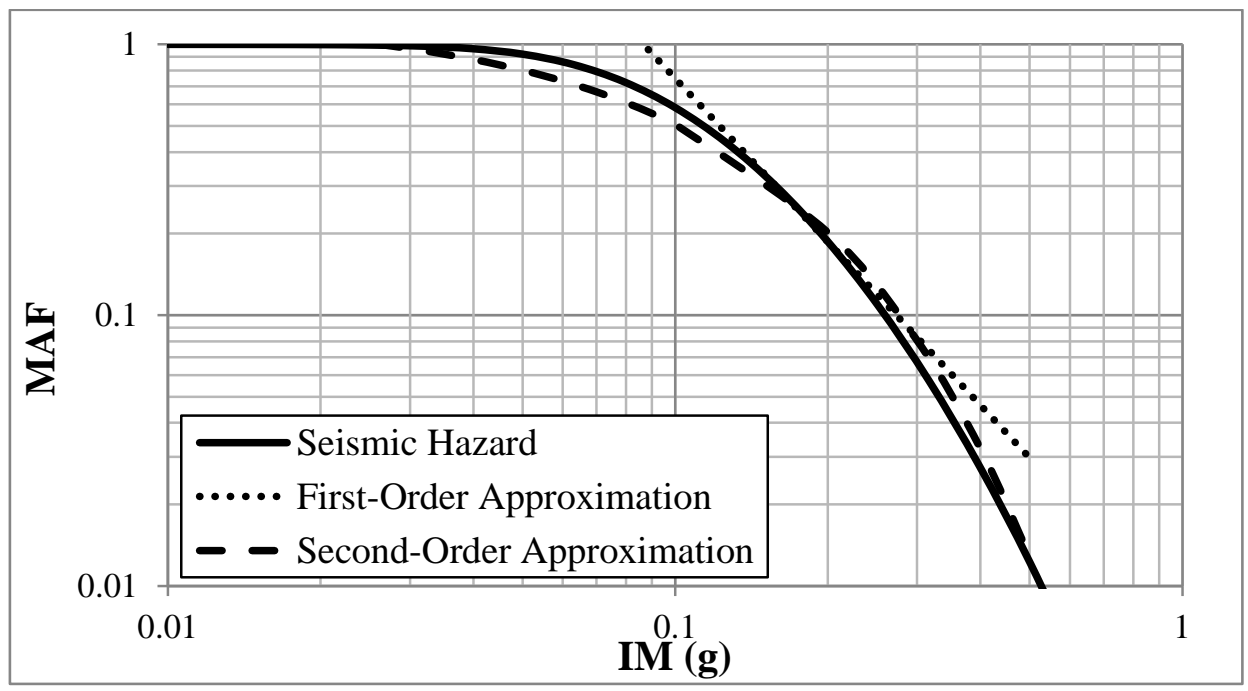

Figure 2. 5\% damp spectral acceleration seismic hazard curve for $\mathrm{T}=1 \mathrm{~s}$ at Central Los Angeles, California, and the first and second order approximations using Eqns 4 and 9 in the vicinity of $\mathrm{IM}=0.18 \mathrm{~g}$.

In order to reduce this error, a second-order approximation was proposed (Vamvatsikos 2013), as follows

$$
H(I M) \cong k_{0} \exp \left(-k_{2} \ln ^{2} I M-k_{1} \ln I M\right)
$$

where $k_{2} \geq 0$ denotes the curvature of the seismic hazard model in log-log space and $k_{0}, k_{1}>0$. Subsequently, Eqn 5 is re-written (Vamvatsikos 2013), as follows 


$$
P[D M \geq L S]=\sqrt{p} k_{0}^{1-p}\left[H\left(I M^{L S}\right)\right]^{p} \exp \left[\frac{1}{2} p \frac{k_{1}^{2}}{b^{2}} \beta_{D M \mid I M}^{2}\right]
$$

where

$$
p=\frac{1}{1+2 k_{2} \beta_{D M \mid I M}^{2}}
$$

Furthermore, similar to the approximation of seismic hazard, alternative distribution models have been suggested for the DM-IM relation such as a linear model in semi-log space (Romão et al. 2013).

\section{UNCERTAINTY QUANTIFICATION and HYBRID SIMULATION}

In the presence of uncertainties, the seismic risk to civil structures cannot be eliminated. Nevertheless, it must be managed by engineers, code-writers and other regulatory authorities (Ellingwood and Kinali 2009). In this regard, it is essential to primarily distinguish between the types of uncertainties in order to identify their sources (Kiureghian and Ditlevsen 2009). The uncertainty which is assumed to be the intrinsic randomness of a phenomenon is referred to as aleatoric and the epistemic uncertainty is the one which is caused by lack of knowledge or seismic data, imperfect modelling, and simplification (Celik and Ellingwood 2010). For example, it is generally understood that the seismic hazard curves (maps), which are provided by the seismic codes, represent the mean seismic hazard. The assumption of hazard levels according to these curves represents the aleatoric uncertainty while the epistemic uncertainty is associated with the plausible alternative ground motion models, which are averaged to obtain the mean hazard (Abrahamson and Bommer 2005). In seismic risk analysis, the sources of uncertainty which arise from the ambiguities in structural and modelling parameters are mainly attributed to the epistemic uncertainty (Paté-Cornell 1996). 


\subsection{Uncertainty Modelling}

The conventional approach for uncertainty quantification in fragility analysis was the application of confidence interval method (Ellingwood and Kinali 2009). The shortcomings of this approach were the high sensitivity of the predicted results to the level of confidence chosen and the need for distinguishing between aleatory and epistemic uncertainties, which is a subjective and debatable distinction (Liel et al. 2009). Cornell et al. (2002) challenged the idea that using a mean estimation of $P_{O F}$, rather than the median estimate (Eqn 6), can capture the effect of uncertainty in the same fragility function:

$$
\bar{P}_{o F}=\bar{H}\left(s_{a}{ }^{C}\right) \exp \left[\frac{1}{2} \frac{k_{1}^{2}}{b^{2}}\left(\beta_{D R}^{2}+\beta_{D U}^{2}+\beta_{C R}^{2}+\beta_{C U}^{2}\right)\right]
$$

In this regard, the dispersion measures $\beta_{D R}$ and $\beta_{C R}$, which were denoted as $\beta_{D \mid S_{a}}$ and $\beta_{C}$ in the previous section, highlight the effect of randomness while, $\beta_{D U}$ and $\beta_{C U}$ reflect the dispersion measures according to an epistemic uncertainty source. Albeit, Yun et al. (2002) clarified that this generic development of uncertainty can be expanded to involve a larger set of dispersions such as uncertainty associated with damping estimation $\left(\beta_{\text {damping }}\right)$, live load $\left(\beta_{\text {live load }}\right)$, and material properties $\left(\beta_{\text {material properties }}\right)$.

There are two major approaches in uncertainty quantification. In the forward approach (uncertainty propagation), the output results of numerical modelling and dynamic analysis are evaluated to reflect the uncertain input data usually by a mean and variance measure (Lee and Chen 2009). Majority of uncertainty analysis techniques was developed for uncertainty propagation problems (Lee and Chen 2009). In this regard, different sources of uncertainty were investigated, in relation to record selection (Padgett and DesRoches 2007), material strength and structural component stiffness (Somja et al. 2013; Celik and Ellingwood 2010; Vamvatsikos and Fragiadakis 2010; Liel et al. 2009; Padgett and DesRoches 2007; Montiel 
and Ruiz 2007), structural damping ratio (Celik and Ellingwood 2010), gross geometry (Padgett and DesRoches 2007), structural capacity and system loads (Liel et al. 2009; Tesfamariam and Sadiq 2006; Montiel and Ruiz 2007), support or connection conditions (Celik and Ellingwood 2010), influences of partition walls and other non-structural elements, and two-dimensional modelling of three-dimensional structures (Ellingwood 2001).

\subsection{Hybrid Simulation}

The other approach in uncertainty analysis, namely the hybrid simulation, is an inverse uncertainty quantification in which the discrepancies between the experimental measurements of a system and the numerical simulation results, and subsequently the uncertainties in the model, are estimated (model calibrating) (Matthies 2007). However this approach is more difficult to adopt than the forward uncertainty propagation, nevertheless, hybrid simulation has the advantage that the numerical modelling results can be updated by the measured data (Mottershead and Friswell 1993). The resulting fragility curves, in this case, are called the hybrid fragility curves.

In this regard, Singhal and Kiremidjian (1998) presented a Bayesian approach to update analytical fragility functions of RC frame buildings using the observational damage data from the 1994 Northridge earthquake. Nevertheless, because of the limited data covering only six levels of ground motion intensities, the fragility functions were updated at discrete points. Similarly, Kappos et al. (1998) used the empirical 1978 Thessaloniki (Greece) earthquake data to validate the numerically calculated damage fragility matrices for seismic loss evaluation of reinforced concrete buildings. In addition, Karim and Yamazaki (2001) verified the numerically constructed fragility curves for bridge piers against the empirical fragility curves, which were developed based on damage data from the 1995 Kobe earthquake. Moreover, Banerjee and Shinozuka (2008b) developed a mechanistic model for investigating 
the seismic vulnerability of concrete bridges in the form of fragility curves. The optimal choices of the threshold limit-state values, in this model, were calibrated by the empirical fragility curves which were derived based on the 1994 Northridge earthquake damage data.

Experimental studies can also be a source data for calibrating analytical fragility curves. In this regard, Kwon and Elnashai (2006) used the results of shaking table test of a one-third scale ordinary three-story moment resisting RC frame to calibrate the analytical fragility curves considering material and ground motion uncertainties. The use of large scale experimental tests, for calibrating and updating the analytical fragility curves, has been considered by other researchers as well (Banerjee and Shinozuka, 2008a; Kramar et al. 2010; Banerjee and Chi 2013). In comparison to the use of empirically collected data for updating the numerical model of the structure, using a large scale experimental test results in a more reliable updated model because sufficient detailed data can be obtained. Nevertheless, the cost of large scale testing is worth noting. To overcome this shortcoming, a Bayesian approach was proposed, by Koutsourelakis (2010), which has the advantage of estimating the empirical seismic data samples for the whole range of values of ground motion intensity. Subsequently, unlike the approach proposed by Singhal and Kiremidjian (1998), which requires at least one measured seismic data sample for each level of ground shaking, the entire fragility function can be updated with limited measured data. Furthermore, Lin et al. (2012) recently proposed a procedure for performing hybrid fragility analysis, using multiple data sources, for an integrated seismic risk assessment (see Figure 3). A typical procedure like Figure 4 may have been developed to encourage the researchers, in the various areas of earthquake risk analysis, to investigate the seismic risk problems across different engineering disciplines, however, raising the interests is not so simple when taking the costs of the whole process into consideration. 


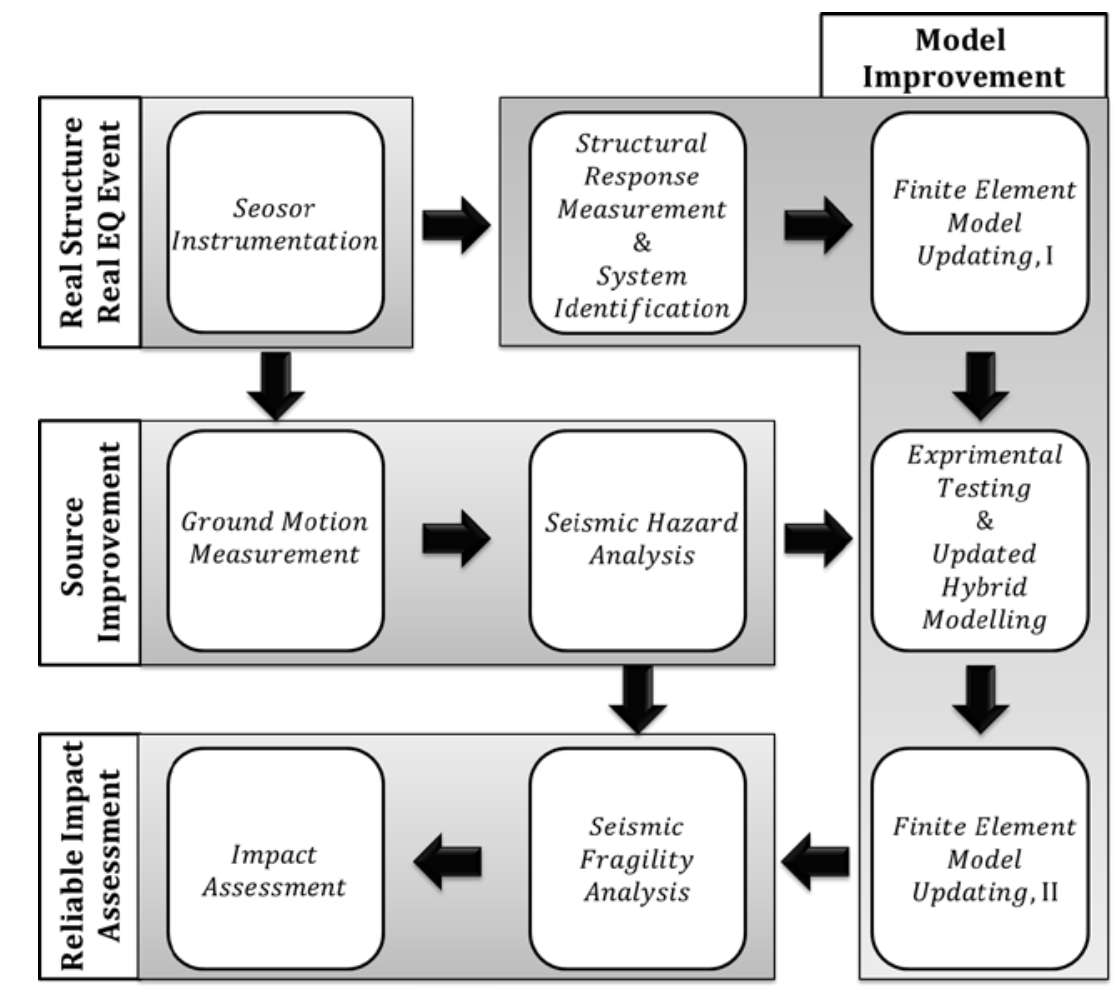

Figure 3. The proposed integrated framework for seismic risk assessment by Lin et al.

\subsection{System-Level Reliability}

An important issue in fragility analysis is to assess the reliability and safety of structures for the whole structural system (Ditlevsen and Madsen 1996). A major difficulty in this regard is defining and computing the system-level failure event probability, under seismic hazards, as a function of component-level failure events. Initial approaches to establish system-level failure events relied on the expert opinion (judgmental fragility analysis) and reflecting the overall performance of the system, in terms of residual capacity as a function of structural damage (ATC-40 1996). In this regard, seismic system failure events are defined based on empirical data from post-earthquake inspection to correlate structural damage and overall performance of the system. However, as discussed before, using judgmental fragility analysis has major shortcomings. 
Early attempts for evaluating analytical system-level reliability (fragility curve) were based on computation of confidence bounds (from statistically-independent to fully-coupled) to investigate the correlated performance of the system components (Song and Kiureghian 2003; Choi et al. 2004). These studies revealed that the total system reliability at a particular limit-state is the union of the reliabilities of the system components in the same limit-state:

$$
P\left[\text { Fail }_{\text {system }}\right]=\bigcup_{i=1}^{n} P\left[\text { Fail }_{\text {component }-i}\right]
$$

in which the upper and lower bounds of the system are as follows:

$$
\max _{i=1}^{n}\left[P\left(\text { Fail }_{\text {component }-i}\right)\right] \leq P\left(\text { Fail }_{\text {system }}\right) \leq 1-\prod_{i=1}^{n}\left[1-P\left(\text { Fail }_{\text {component }-i}\right)\right]
$$

An important issue which should be considered here is the effect of the interval space between the two typical consecutive seismic demand limit-states $j$ and $j-1$, as shown in Figure 4, on the probability of the system-level failure event. To investigate this issue, Dueñas-Osorio and Padgett (2011) described that the probability of the overall performance of the system exceeding the seismic demand limit-state $j$, is coupled with the simultaneous failure of all important components in the previous limit-state $j-1$. Therefore, a wider confidence bound was proposed in order to assess the system-level reliability at the limitstate $j$, namely the augmented system-level failure (Dueñas-Osorio and Padgett 2011):

$$
P_{\text {augmented }_{j}}=P_{\text {typical }_{j}}+P_{\text {interval }_{j \& j-1}}
$$

where $P_{\text {typical }}$ and $P_{\text {interval }}$ are illustrated in Figure 5. The effect of an augmented failure event on a typical system was quantified to be a $4 \%-20 \%$ change in the median moderate limit-state in fragility analysis (Dueñas-Osorio and Padgett 2011). 


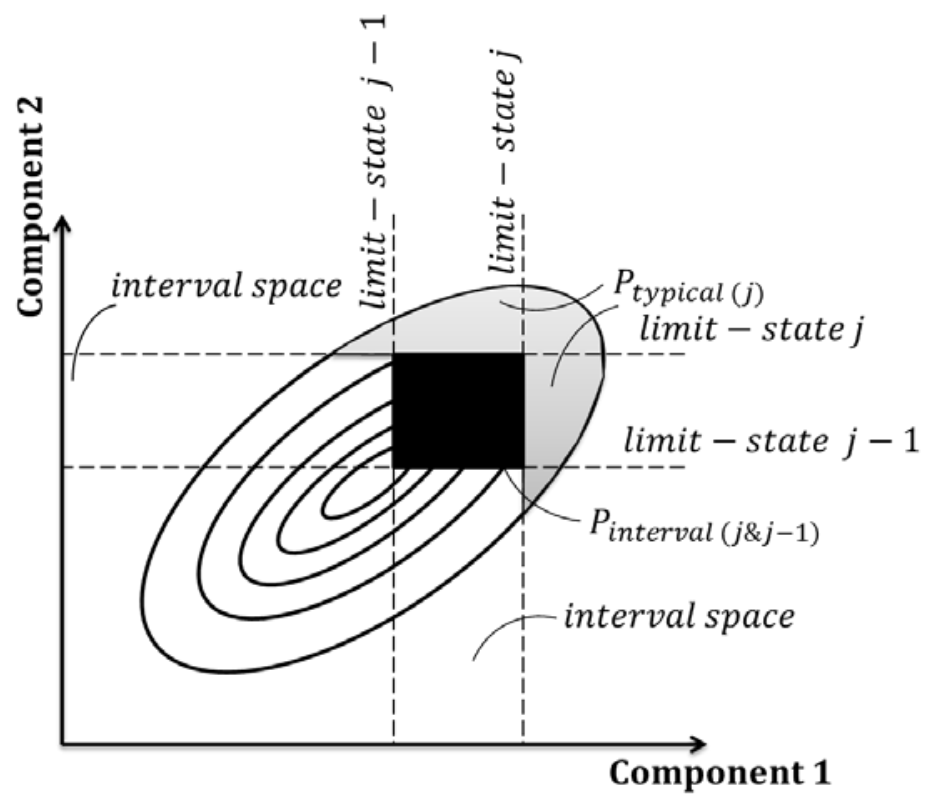

Figure 4. The borders of consecutive limit-states and the domains of typical and augmented failure probability of the whole system

To improve the reliability bounds, Monte Carlo Simulation (MCS) had been used (Nielson and DesRoches 2007). Nevertheless, system-level failure definitions range from considering a single structural component failure to simultaneous failure of all components. Thus, the use of traditional MCS may become computationally demanding given that each definition of system-level failure events requires a full numerical simulation. An alternative to reduce the computational cost is to use MCS in combination with Response Surface Methodology (RSM), because the simulation is performed on a polynomial response surface function rather than a complex dynamic model (Towashiraporn 2004). Seo and Linzell (2013) have recently applied RSM for system-level fragility analysis. However, in using RSM it is required to choose the order of the RSM polynomial. In this regard, Stander and Craig (2002) criticised that while a two-polynomial function (linear approximations) results in a rapid solution, it may only be useful within a certain subregion of the design space. On the other hand, in addition to the higher possibility of bias error for a nonlinear estimation, a higher order 
approximation (quadratic polynomials) is time consuming computationally (Stander and Craig 2002). Also, a weighting scheme of component failure can be used for establishing system-level failure based on the contribution of load-carrying capacity, repair cost, or impact on functionality (Tesfamariam and Sadiq 2008; Zhang and Huo 2009). This approach indicates that all the structural components do not influence the system-level failure equally. Nevertheless, a difficulty in application of this approach is establishment of weights for different components because it may bring about additional uncertainties. Moreover, a matrix-based system reliability (MSR) method has been proposed and applied by Song and Kang (2009). Nevertheless, using this method the total number of system failure events, from no component failure to simultaneous failure of all components, is $2^{N}$ where $N$ denotes the number of components. This means that considering an additional structural component, for the system-level fragility analysis, the total probable system-level failure events are doubled and the computation costs rise exponentially.

\section{GROUND MOTION INTENSITY MEASURE}

The ground motion intensity, or simply the intensity measure (IM), is the most significant index to describe the earthquake characteristics from the structural engineering point of view. Considering the fragility analysis formulation (Eqns 1 to 6), it is understood that the seismic fragility curve is a function of IM. Thus, a more appropriate IM, which represents more precisely the ground shaking forces and characteristics, results in more accurate fragility curves.

\subsection{Optimal Intensity Measure}

The list of IMs which was proposed for earthquake engineering is already large and seems to be growing (Ye et al. 2013; Giovenale et al. 2004; Baker and Cornell 2005; Cimellaro et al. 2011; Luco and Cornell 2007; Padgett et al. 2008). Nevertheless, it is important to choose an 
appropriate and comprehensive IM which is correlated with the structural performance. In this regard, several features are defined for an optimal IM. Among these, the most significant and recognised factor is known as "efficiency", which describes the corresponding damage measure (DM) variation according to the given IM in which, a more efficient IM results in relatively less variability (Shome 1999). In other words, applying an efficient IM produces a comparatively smaller dispersion measure of the calculated seismic demand in the non-linear dynamic analyses of the structure which was previously defined as $\beta_{\mathrm{DM} \mid \mathrm{IM}}$ in this study. The benefit in this case is the improvement of the reliability of analysis by reaching a narrower confidence interval band $(\sigma)$ of the conditional median DM value for a given IM level as shown in Figure 5.

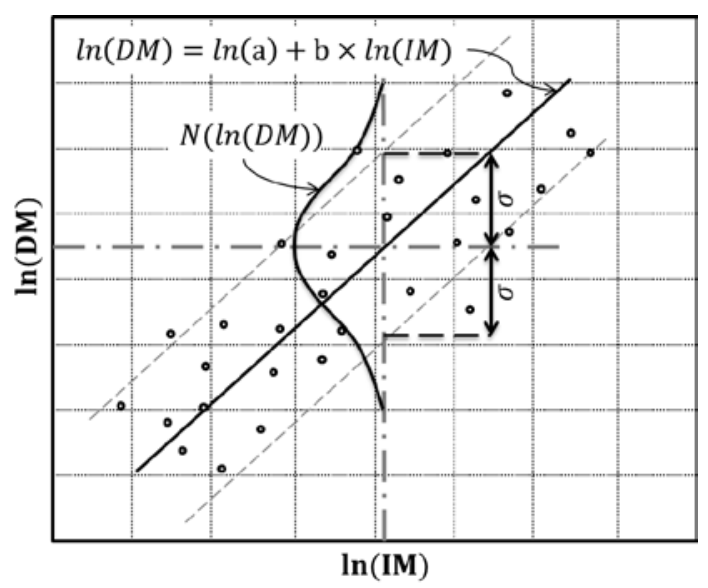

Figure 5. Distribution of the seismic demand in response to shaking intensity in the log-log space

To evaluate the efficiency of an IM, the most direct and rigorous approach is performing the correlation analysis of the DM-IM, for different IMs, through nonlinear time-history analysis (Ye et al. 2013). Nevertheless, the main difficulty of this exercise is that a certain number of nonlinear time-history analyses must be re-scaled and re-run every time a new candidate IM is proposed. An alternative to reduce the amount of computation is to use Incremental Dynamic Analysis (IDA). An IDA curve is a continuous plot of DM versus IM which is 
derived by scaling a record up or down to different IM levels (Vamvatsikos and Cornell 2002). In addition, a stripe analysis technique, as described by Jalayer (2003), can be employed to summarise the IDA curves properly in which stripes of DM values can be generated at any IM values containing as many DM values as the number of records. Subsequently, it is possible to change the IM in terms of the representative DM-IM curves without re-running the analyses. Applying the stripe analysis is, also, beneficial in the way that it does not introduce any bias in the results of DM values using different IM (Jalayer 2003). Also, an approximate method has been introduced by Giovenale et al. (2004) which estimates the DM-IM dispersion to decrease the efforts of re-running the analysis and computational costs.

Padgett et al. (2008) challenged the idea that the direct correlation between the IM and DM should also be considered for assessing the efficiency of an IM. As such, a new feature, namely "practicality", was defined in which an IM is considered practical when the resulting DM is directly dependent upon it. It was explained that the regression parameter "b" (see Eqn 2 and Figure 5) is the index for practicality wherein, a steeper linear IM-DM distribution implies a more practical IM. Subsequently, by combining practicality with efficiency, Padgett et al. (2008) proposed the "proficiency" for assessing optimal IMs. In this regard, the modified dispersion measure shows the practicality which is defined by $\epsilon=\frac{\beta_{\mathrm{DM} \mid \mathrm{IM}}}{\mathrm{b}}$.

Furthermore, an optimal IM should yield DMs conditionally independent of earthquake characteristics (e.g. magnitude (M) and epicentral distance (R)) and site characteristics (e.g. soil and fault type). For example, considering Eqn 1, $P[D M \geq L S \mid I M]$ is the MAF of exceeding each IM value. There is no need to condition Eqn 1 upon additional parameters for a sufficient IM while an insufficient IM requires re-writing the conditional term in the form of $P[D M \geq L S \mid I M, M, R$, ect. $]$. Therefore, a factor namely "sufficiency" was defined which 
is evaluated by performing a regression analysis on the PSDM residuals relative to the ground motion characteristics, $M$ and $R$ (Luco and Cornell 2007). On the other hand, it is noteworthy that hazard maps are normally available for peak ground acceleration (PGA) or alternatively for a discrete number of values of spectral acceleration $\left(S_{a}\right)$. Although novel hazard curves can be calculated for a more efficient new IM through PSHA, the calculation of the corresponding hazard curves might be excessively demanding. Therefore, "hazard computability” was defined by Giovenale et al. (2004) as the effort required in order to determine the hazard curve in PSHA. It was explained that, however, a particular IM may be more efficient or proficient; it may therefore be less desirable because of its hazard computability.

\subsection{Ground Motion Record Selection}

In addition to the defined metrics, as the characteristics of an optimal IM, the number of ground motion records which should be used for scaling and nonlinear dynamic analysis purposes is a factor that influences both the result accuracy and the computational time. In this regard, according to the ASCE/SEI 7-10 (2010), a minimum of three ground motion records is required, and in the case of using less than seven ground motion records, the design value of DM should be taken as the maximum of the resulted DMs. For a higher number of ground motion records the average of the DMs was proposed. Nevertheless, Hancock et al. (2008) discussed that the number of required records to obtain a stable estimate of the response is related to the type of DM used in the analysis. Reyes and Kalkan (2012) also demonstrated that the procedure of ASCE/SEI 7-10 is too conservative in the case of using less than seven records (choosing the maximum DM value). In addition, it was reported that increasing the number of records from 7 to 10 has little effect on the accuracy of the nonlinear analysis results. Moreover, the study by Cimellaro et al. (2011) indicates that the 
minimum number of records for an accurate estimation of seismic demand can be reduced when $S_{a}$ is used instead of PGA.

Also, in addition to the optimum number of required records for an accurate nonlinear dynamic analysis, some qualitative factors have been addressed which influence the record selection such as soil profile (Lee et al. 2000), motion duration (Hancock and Bommer 2007; Iervolino et al. 2006), earthquake magnitude (M) and distance (R) (Elefante et al. 2010), acceleration to velocity ratio (a/v) (Tso et al. 1992), seismotectonic and geophysical parameters (Kawaga et al. 2004).

\section{SEISMIC DAMAGE MEASURE}

Similar to the significance of IM discussed above, seismic damage measure (DM) largely influences the fragility function. This is because the prescribed limit-states (LS) by the seismic codes, which impact the level of calculated failure probability, are highly uncertain and the amount of such an uncertainty varies from one DM to another (Jalayer 2003). Excessive fragility studies have been accomplished using the peak transient displacement of a structure, or simply its lateral story drift, as the DM under seismic loads (Karavasilis et al. 2006; Romão et al. 2013; Günay and Mosalam 2013). However, lateral drift is unable to signal the location and intensity of seismic damage as well as the residual capacity of the structure. On the other hand, inelastic seismic displacements, i.e. the residual deformation, play an important role in defining the seismic performance level by providing an indicator for the effort required to straighten and repair structures. Consequently, the use of residual drift demand, as an alternative to DM, has been recommended for seismic reliability assessment of structures (Ruiz-García and Miranda 2010; Réveillère et al. 2012; Bojórquez and Ruiz-García 2013). The structural ductility ratio has also been utilised for seismic risk analyses to identify the location of possible damage for strengthening purposes (Hong and Hong 2007; Mehani et 
al. 2013; Freddi et al. 2013). However, all the above mentioned DMs still cannot capture the cyclic effects of seismic loads.

The dynamic nature of seismic loads asserts the necessity of provisions to include the impacts of low-cycle fatigue and energy dissipation on structural capacity. A number of DMs have been suggested in the literature to reflect such an impact, namely the cumulative damage indices (Krawinkler and Zohrei 1983; Fajfar 1992; Park and Ang 1985; Cosenza et al. 2009). These indices are particularly most appropriate to be used when investigating the sustainability of structures in aftershocks (Luco et al. 2004), or when a previously damaged structure affected by a sequence of earthquakes is considered (Mander and Rodgers 2013). Moreover, the influence of ground motion duration, which is assumed to affect the total energy induced by earthquake loads (Hancock and Bommer 2007), can be investigated through the cumulative damage theory (Raghunandan and Liel 2013; Iervolino et al. 2006; Teran-Gilmore and Jirsa 2007; Bojórquez et al. 2008). Subsequently, fragility curves have been developed using the cumulative damage indices as the DM in a fragility function (Hwang and Huo 1994; Singhal and Kiremidjian 1996; Karim and Yamazaki 2001; Khaloo and Tonekaboni 2013; Bojórquez et al. 2008).

\section{JOINT IMPACT in FRAGILITY ANALYSIS}

In infrastructure management, in order for the structure to preserve its sustainability during its life-cycle, it is particularly important to analyse the failure risk not only for the seismic events but also for other hazards. Recent advances in computational methods have provided the possibility of performing compound risk analysis of structures in highly critical conditions. In this regard, some researchers attempted to combine the seismic fragility analysis of structures with additional hazards probability. 


\subsection{Environmental Deterioration}

Using the current guidelines for seismic performance assessment of structures (FEMA 273 1997; FEMA 274 1997; FEMA 356 2000; ASCE 41-06 2007), the structural capacity is calculated as time-independent. This issue is at odds with the accurate condition of ageing structures in deteriorating environmental situation which influences the structural capacity. Choe et al. (2008) primarily developed a seismic drift and shear force capacity model for corroded RC structures. In their study, the combination of time-dependent corrosion rate and seismic fragility was presented by calculating the chloride-induced corroded structural capacity and related fragility curve in various time intervals. Kumar et al. (2009) considered the effects of chloride-induced corrosion of steel reinforcement in RC bridges for seismic fragility analysis with special attention to the seismic damage accumulation. Akiyama et al. (2011) investigated a procedure for integrating the effects of airborne chloride in marine environments with seismic reliability estimation of RC bridge piers. In addition to the environmental deteriorating condition, as a long-term effect of ageing of structures, it was suggested that the influences of accelerating deteriorating factors (e.g. de-icing salt) should be taken into consideration. To reflect the ageing effects, Vamvatsikos and Dolšek (2011) proposed a closed-form solution, based on the equivalent constant rate (ECR) which was introduced by Yeo and Cornell (2009) for post-quake environment decision-making. In addition, Ghosh and Padgett (2010) developed time-dependent seismic fragility curves in which instead of decreasing the structural capacity over time, the seismic demand was considered to be increasing as a function of time. The impact of aging was then illustrated not only for the fragility of structural components but also for the reliability of the whole system. 


\subsection{Soil-Structure Interaction}

Bedrock configuration and soil characteristics play a significant role in preserving the general stability and system reliability of a structure. Seismic fragility analysis of structures is often performed without consideration of soil-structure interaction (SSI) in that the base of the structure is usually assumed to be fixed. The most common approach to consider the flexibility of the foundation is using a lumped spring model where the properties are accounted for based on the field tests. A seismic fragility analysis of bridges, carried out by Kwon and Elnashai (2007), shows that the embankment and abutment behave highly nonlinear with soil material model which is incomparable to the simplified lumped spring model. On the other hand, soil liquefaction is a serious problem during an earthquake which may result in ground subsidence, loss of bearing capacity, shifting/tilting of foundation, pile failure, slope/embankment failure, abutment failure, lateral spreading, and subsequently the instability of the structure (Bignell and LaFave 2009).

Koutsourelakis et al. (2002) established seismic fragility curves for soil-structure systems due to soil liquefaction by considering the variability of soil parameters. Zhang et al. (2008) evaluated the seismic fragility curves of structures subjected to both dynamic loads and liquefaction-induced lateral spreading, based on nonlinear dynamic and equivalent static procedures. It was reported that structures demonstrate different seismic capacities under seismic loads and lateral spreading. Other researchers discussed that the seismic fragility due to soil liquefaction should be taken into consideration the same way as the structural component fragility for the system-level failure fragility analysis (Bignell and LaFave 2010; Aygün et al. 2011). A case study by Padgett et al. (2010) shows that the seismic fragility, in this regard, is influenced by the variation in some of the soil modelling parameters such as undrained shear strength of soil, soil shear modulus, gap between deck and abutment, ultimate capacity of soil, and fixed and expansion bearing coefficients of friction. Moreover, 
Wang et al. (2013) reported that inclusion of vertical ground motions (VGM) in seismic fragility analysis of coupled structure-soil-foundation systems, with liquefaction potential, influences the failure probability that neglecting VGM results in underestimating the probability of failure.

\subsection{Multi-Hazard Analysis}

Although in the most of geographical locations one natural hazard is dominant, in some certain areas multiple hazards threaten the safety of structures. The multi-hazard analysis is the state-of-the-art in structural performance-based design since it considers more than a single hazard, during the life-cycle of a structure, to increase the structural safety and reduce subsequent costs of rehabilitation. In addition, a multi-hazard analysis can support the improvements in design and construction practices, insurance underwriting, and planning for the community's response to disasters. For this reason, additional hazard sources such as snow loads (Lee and Rosowsky 2006), hurricanes (Li and Ellingwood 2009), and floods (Banerjee and Prasad 2011; Dong et al. 2013) were considered by some researchers in addition to the seismic fragility analysis. Nevertheless, the main challenge in multi-hazard analysis is optimisation of the allocation of hazard mitigation resources.

\section{SUMMARY, RECOMMENDATIONS and PROSPECTIVES}

Extensive research on seismic risk and reliability has brought about a significant advancement for mitigation and recovery, as well as preparedness and response against seismic hazard. However, there still remain some limitations with regard to the calculation process of seismic fragility and structural reliability. Although the use of power model approximations for estimating seismic hazard and DM-IM distribution make the closed-form solution quite rapid and appealing, the inherent errors of such a solution are non-negligible. Nevertheless, these errors can be reduced by employing a bilinear or trilinear DM-IM 
distribution or higher-order (e.g. second-order or fractional-order) approximations of seismic hazard. In addition, the discussion on the uncertainty quantification and the methods for system-level reliability assessments has revealed that the current methods either demand large time/memory or use simplifying assumptions.

Moreover, the studies on fragility analysis using alternative IM and DM have been reviewed. To present the most optimal IMs, the list of those available is reduced to the Peak Ground Acceleration (PGA) and the spectral acceleration at the fundamental period of a structure $\mathrm{Sa}\left(\mathrm{T}_{1}\right)$. The latter, being a structure-specific IM, is proven to be more efficient than the former. Albeit, using $\mathrm{Sa}\left(\mathrm{T}_{1}\right)$, the contributions of higher modes to the overall dynamic response and the increase of the fundamental period of structure associated with non-linear behaviour are ignored.

The principal uncertainty in fragility analysis, however, arises from the prescriptive limitstates (LS) and structural capacities. More seismic data are required to be collected, from real seismic events and/or full-size experimental tests, to confidently express the structuralspecific LS. Meanwhile, the use of confidence bound methods seems to be an appropriate approach for reflecting the existing uncertainty of LS in fragility curves. Also, using threshold drift values for evaluating cumulative LS in some studies is in contrast with the theories of low-cycle fatigue. Therefore, energy dissipation and cumulative LS must be reevaluated by further research.

With regard to the DM selection, gradual changes of the modal parameters will be of great significance in future investigations. Such a DM also allows the study of the effective contribution of ground motion duration on seismic responses by plotting the changes of modal parameters against the ground motion record time, giving consideration for varying time interval. Furthermore, in depth studies of multi-hazard analysis through fragility 
functions are highly acknowledged, however the circumstances of occurrence of coupled hazards need to be justified more clearly.

\section{CONCLUSION}

A review of literature is presented herein covering the current methods of practice for seismic reliability and risk assessment of structures based on fragility analysis, and recent improvements of these methods of analysis. Major achievements and inherent limitations have also been discussed. Research on seismic fragility analysis is still very active because the fragility curves can be used in risk assessment and mitigation planning for a community's long-term strategy to reduce seismic damage and losses. The research gaps identified have motivated the proposed area of study and assisted in formulating the future research directions.

\section{REFERENCES}

Abrahamson, N.A. and Bommer, J.J. (2005). "Probability and Uncertainty in Seismic Hazard Analysis", Earthquake Spectra, Vol. 21, No. 2, pp. 603-607.

Akiyama, M., Frangopol, D.M. and Matsuzaki, H. (2011). "Life-Cycle Reliability of RC Bridge Piers under Seismic and Airborne Chloride Hazards", Earthquake Engineering \& Structural Dynamics, Vol. 40, No. 15, pp. 1671-1687.

ASCE/SEI 41-06 (2007). Seismic Rehabilitation of Existing Buildings, American Society of Civil Engineers, Reston, VA, USA.

ASCE/SEI SEI 7-10 (2010). Minimum Design Loads for Buildings and Other Structures, American Society of Civil Engineers, Reston, VA, USA.

Aslani, H. and Miranda, E. (2005). "Probability-Based Seismic Response Analysis", Engineering Structures, Vol. 27, No. 8, pp. 1151-1163. 
ATC-40 (1996). Seismic Evaluation and Retrofit of Concrete Buildings Volume 1, Applied Technology Council, Redwood City, CA, USA.

Aygün, B., Duẽas-Osorio, L., Padgett, J.E. and Desroches, R. (2011). "Efficient Longitudinal Seismic Fragility Assessment of a Multispan Continuous Steel Bridge on Liquefiable Soils", Journal of Bridge Engineering, Vol. 16, No. 1, pp. 93-107.

Baker, J.W. and Cornell, C.A. (2005). "A Vector-Valued Ground Motion Intensity Measure Consisting of Spectral Acceleration and Epsilon", Earthquake Engineering \& Structural Dynamics, Vol. 34, No. 10, pp. 1193-1217.

Banerjee, S. and Chi, C. (2013). "State-Dependent Fragility Curves of Bridges Based on Vibration Measurements", Probabilistic Engineering Mechanics, Vol. 33, pp. 116-125.

Banerjee, S. and Prasad, G.G. (2011) "Analysis of Bridge Performance under the Combined Effect of Earthquake and Flood-Induced Scour", Vulnerability, Uncertainty, and Risk: Analysis, Modelling, and Management, B. M. Ayyub, ed., Hyattsville, Maryland, USA, April, pp. 889-896.

Banerjee, S. and Shinozuka, M. (2008a). "Experimental Verification of Bridge Seismic Damage States Quantified by Calibrating Analytical Models with Empirical Field Data", Earthquake Engineering and Engineering Vibration, Vol. 7, No. 4, pp. 383-393.

Banerjee, S. and Shinozuka, M. (2008b). "Mechanistic Quantification of RC Bridge Damage States under Earthquake through Fragility Analysis", Probabilistic Engineering Mechanics, Vol. 23, No. 1, pp. 12-22.

Basoz, N.I., Kiremidjian, A.S., King, S.A. and Law, K.H. (1999). "Statistical Analysis of Bridge Damage Data from the 1994 Northridge, Ca, Earthquake", Earthquake Spectra, Vol. 15, No. 1, pp. 25-54.

Bazzurro, P. (1998). Probabilistic Seismic Demand Analysis, PhD Thesis, Stanford University, CA, USA. 
Benjamin, J.R. and Cornell, C.A. (1975). Probability, Statistics and Decision for Civil Engineers, McGraw-Hill, New York, USA.

Bignell, J. and LaFave, J. (2009). "Analytical Fragility Analysis of Southern Illinois Wall Pier Supported Highway Bridges", Earthquake Engineering \& Structural Dynamics, Vol. 39, No. 7, pp. 709-729.

Bojorquez, E., Ruiz, S.E. and Teran-Gilmore, A. (2008). "Reliability-Based Evaluation of Steel Structures Using Energy Concepts", Engineering Structures, Vol. 30, No. 6, pp. 1745-1759.

Bojórquez, E. and Ruiz-García, J. (2013). "Residual Drift Demands in Moment-Resisting Steel Frames Subjected to Narrow-Band Earthquake Ground Motions", Earthquake Engineering \& Structural Dynamics, Vol. 42, No. 11, pp. 1583-1598.

Bothara, J.K., Dhakal, R.P. and Mander, J.B. (2010). "Seismic Performance of an Unreinforced Masonry Building: An Experimental Investigation", Earthquake Engineering \& Structural Dynamics, Vol. 39, No. 1, pp. 45-68.

Bradley, B.A. and Dhakal, R.P. (2008). "Error Estimation of Closed-Form Solution for Annual Rate of Structural Collapse", Earthquake Engineering \& Structural Dynamics, Vol. 37, No. 15, pp. 1721-1737.

Carballo, J. E. and Cornell, C. A. (2000). Probabilistic Seismic Demand Analysis: Spectrum Matching and Design, Report No. RMS-41, 313, Stanford University, CA, USA.

Celik, O.C. and Ellingwood, B.R. (2010). "Seismic Fragilities for Non-Ductile Reinforced Concrete Frames - Role of Aleatoric and Epistemic Uncertainties", Structural Safety, Vol. 32, No. 1, pp. 1-12.

Choe, D.E., Gardoni, P., Rosowsky, D.V. and Haukaas, T. (2008). "Probabilistic Capacity Models and Seismic Fragility Estimates for RC Columns Subject to Corrosion", Reliability Engineering \& System Safety, Vol. 93, No. 3, pp. 383-393. 
Choi, E.S., DesRoches, R. and Nielson, B. (2004). "Seismic Fragility of Typical Bridges in Moderate Seismic Zones", Engineering Structures, Vol. 26, No. 2, pp. 187-199.

Cimellaro, G.P., Reinhorn, A.M., D'Ambrisi, A. and De Stefano, M. (2011). "Fragility Analysis and Seismic Record Selection", Journal of Structural Engineering, Vol. 137, No. 3, pp. 379-390.

Cornell, C.A. (1968). "Engineering Seismic Risk Analysis", Bulletin of the Seismological Society of America, Vol. 58, No. 5, pp. 1583-\&.

Cornell, C.A., Jalayer, F., Hamburger, R.O. and Foutch, D.A. (2002). "Probabilistic Basis for 2000 Sac Federal Emergency Management Agency Steel Moment Frame Guidelines", Journal of Structural Engineering, Vol. 128, No. 4, pp. 526-533.

Cornell, C.A. and Krawinkler, H. (2000). "Progress and Challenges in Seismic Performance Assessment." PEER Center News, pp. 1-3.

Cosenza, E., Manfredi, G. and Polese, M. (2009). "Simplified Method to Include Cumulative Damage in the Seismic Response of Single-Degree-of-Freedom Systems", Journal of Engineering Mechanics, Vol. 135, No. 10, pp. 1081-1088.

D’Ayala, D.F. and Paganoni, S. (2011). "Assessment and Analysis of Damage in L'aquila Historic City Centre after 6th April 2009", Bulletin of Earthquake Engineering, Vol. 9, No. 1, pp. 81-104.

Ditlevsen, O. and Madsen, H O. (1996). Structural Reliability Methods, John Wiley \& Sons, Chichester, UK.

Dong, Y., Frangopol, D.M. and Saydam, D. (2013). "Time-Variant Sustainability Assessment of Seismically Vulnerable Bridges Subjected to Multiple Hazards", Earthquake Engineering \& Structural Dynamics, Vol. 42, No. 10, pp. 1451-1467. 
Dueñas-Osorio, L. and Padgett, J.E. (2011). "Seismic Reliability Assessment of Bridges with User-Defined System Failure Events", Journal of Engineering Mechanics, Vol. 137, No. 10, pp. 680-690.

Elefante, L., Jalayer, F., Iervolino, I. and Manfredi, G. (2010). "Disaggregation-Based Response Weighting Scheme for Seismic Risk Assessment of Structures", Soil Dynamics and Earthquake Engineering, Vol. 30, No. 12, pp. 1513-1527.

Ellingwood, B.R. (2001). "Earthquake Risk Assessment of Building Structures", Reliability Engineering \& System Safety, Vol. 74, No. 3, pp. 251-262.

Ellingwood, B.R. and Kinali, K. (2009). "Quantifying and Communicating Uncertainty in Seismic Risk Assessment", Structural Safety, Vol. 31, No. 2, pp. 179-187.

Fajfar, P. (1992). "Equivalent Ductility Factors, Taking into Account Low-Cycle Fatigue", Earthquake Engineering \& Structural Dynamics, Vol. 21, No. 10, pp. 837-848.

Fajfar, P. and Dolšek, M. (2012). "A Practice-Oriented Estimation of the Failure Probability of Building Structures", Earthquake Engineering \& Structural Dynamics, Vol. 41, No. 3, pp. 531-547.

FEMA 274 (1997a). NEHRP Commentary on the Guidelines for the Seismic Rehabilitation of Buildings, Federal Emergency Management Agency, Washington, D.C., USA.

FEMA 273 (1997b). NEHRP Guidelines for the seismic rehabilitation of buildings, Federal Emergency Management Agency, Washington, D.C., USA

FEMA 356 (2000). Pre-standard and Commentary for the Seismic Rehabilitation of Buildings, Federal Emergency Management Agency, Washington, D.C., USA

Fragiadakis, M. and Vamvatsikos, D. (2010). "Fast Performance Uncertainty Estimation Via Pushover and Approximate Ida", Earthquake Engineering \& Structural Dynamics, Vol. 39, No. 6, pp. 683-703. 
Freddi, F., Tubaldi, E., Ragni, L. and Dall'Asta, A. (2013). "Probabilistic Performance Assessment of Low-Ductility Reinforced Concrete Frames Retrofitted with Dissipative Braces", Earthquake Engineering \& Structural Dynamics, Vol. 42, No. 7, pp. 993-1011.

Ghosh, J. and Padgett, J.E. (2010). "Aging Considerations in the Development of TimeDependent Seismic Fragility Curves", Journal of Structural Engineering, Vol. 136, No. 12, pp. 1497-1511.

Giovenale, P., Cornell, C.A. and Esteva, L. (2004). "Comparing the Adequacy of Alternative Ground Motion Intensity Measures for the Estimation of Structural Responses", Earthquake Engineering \& Structural Dynamics, Vol. 33, No. 8, pp. 951-979.

Günay, S. and Mosalam, K.M. (2013). "Peer Performance-Based Earthquake Engineering Methodology, Revisited", Journal of Earthquake Engineering, Vol. 17, No. 6, pp. 829858.

Hancock, J. and Bommer, J.J. (2007). "Using Spectral Matched Records to Explore the Influence of Strong-Motion Duration on Inelastic Structural Response", Soil Dynamics and Earthquake Engineering, Vol. 27, No. 4, pp. 291-299.

Hancock, J., Bommer, J.J. and Stafford, P.J. (2008). "Numbers of Scaled and Matched Accelerograms Required for Inelastic Dynamic Analyses", Earthquake Engineering \& Structural Dynamics, Vol. 37, No. 14, pp. 1585-1607.

Hazus. (2014). Hazus: The Federal Emergency Management Agency's (FEMA's) Methodology for Estimating Potential Losses from Disasters. http://www.fema.gov/hazus. Hong, H.P. and Hong, P. (2007). "Assessment of Ductility Demand and Reliability of Bilinear Single-Degree-of-Freedom Systems under Earthquake Loading", Canadian Journal of Civil Engineering, Vol. 34, No. 12, pp. 1606-1615.

Hwang, H.H.M. and Huo, J.R. (1994). "Generation of Hazard-Consistent Fragility Curves", Soil Dynamics and Earthquake Engineering, Vol. 13, No. 5, pp. 345-354. 
Hwang, H.H.M. and Jaw, J.W. (1990). "Probabilistic Damage Analysis of Structures", Journal of Structural Engineering, Vol. 116, No. 7, pp. 1992-2007.

Iervolino, I., Manfredi, G. and Cosenza, E. (2006). "Ground Motion Duration Effects on Nonlinear Seismic Response", Earthquake Engineering \& Structural Dynamics, Vol. 35, No. 1, pp. 21-38.

Jalayer, F. (2003). Direct Probabilistic Seismic Analysis: Implementing Non-Linear Dynamic Assessments, PhD Thesis, Stanford University, CA, USA.

Kagawa, T., Irikura, K. and Somerville, P.G. (2004). "Differences in Ground Motion and Fault Rupture Process between the Surface and Buried Rupture Earthquakes", Earth Planets and Space, Vol. 56, No. 1, pp. 3-14.

Kaplan, S., Perla, H.F. and Bley, D.C. (1983). "A Methodology for Seismic Risk Analysis of Nuclear Power Plants", Risk Analysis, Vol. 3, No. 3, pp. 169-180.

Kappos, A.J., Stylianidis, K.C. and Pitilakis, K. (1998). "Development of Seismic Risk Scenarios Based on a Hybrid Method of Vulnerability Assessment", Natural Hazards, Vol. 17, No. 2, pp. 177-192.

Karavasilis, T.L., Bazeos, N. and Beskos, D.E. (2006). "Maximum Displacement Profiles for the Performance Based Seismic Design of Plane Steel Moment Resisting Frames", Engineering Structures, Vol. 28, No. 1, pp. 9-22.

Karim, K.R. and Yamazaki, F. (2001). "Effect of Earthquake Ground Motions on Fragility Curves of Highway Bridge Piers Based on Numerical Simulation", Earthquake Engineering \& Structural Dynamics, Vol. 30, No. 12, pp. 1839-1856.

Kennedy, R.P., Cornell, C.A., Campbell, R.D., Kaplan, S. and Perla, H.F. (1980). "Probabilistic Seismic Safety Study of an Existing Nuclear Power Plant", Nuclear Engineering and Design, Vol. 59, No. 2, pp. 315-338. 
Khalfan, M. (2013). Fragility Curves for Residential Buildings in Developing Countries: A Case Study on Non-Engineered Unreinforced Masonry Homes in Bantul, Indonesia, MSc Thesis, McMaster University, ON, Canada.

Khaloo, A. and Tonekaboni, M. (2013). "Risk Based Seismic Assessment of Structures", Advances in Structural Engineering, Vol. 16, No. 2, pp. 307-314.

Kircher, C.A., Whitman, R.V. and Holmes, W.T. (2006). "Hazus Earthquake Loss Estimation Methods", Natural Hazards Review, Vol. 7, No. 2, pp. 45-59.

Kiureghian, A.D. and Ditlevsen, O. (2009). "Aleatory or Epistemic? Does It Matter?", Structural Safety, Vol. 31, No. 2, pp. 105-112.

Koutsourelakis, P.S. (2010). "Assessing Structural Vulnerability against Earthquakes Using Multi-Dimensional Fragility Surfaces: A Bayesian Framework", Probabilistic Engineering Mechanics, Vol. 25, No. 1, pp. 49-60.

Koutsourelakis, S., Prévost, J.H. and Deodatis, G. (2002). "Risk Assessment of an Interacting Structure-Soil System Due to Liquefaction", Earthquake Engineering \& Structural Dynamics, Vol. 31, No. 4, pp. 851-879.

Kramar, M., Isaković, T. and Fischinger, M. (2009). "Seismic Collapse Risk of Precast Industrial Buildings with Strong Connections", Earthquake Engineering \& Structural Dynamics, Vol. 39, No. 8, pp. 847-868.

Krawinkler, H. and Zohrei, M. (1983). "Cumulative Damage in Steel Structures Subjected to Earthquake Ground Motions", Computers \& Structures, Vol. 16, No. 1-4, pp. 531-541.

Kumar, R., Gardoni, P. and Sanchez-Silva, M. (2009). "Effect of Cumulative Seismic Damage and Corrosion on the Life-Cycle Cost of Reinforced Concrete Bridges", Earthquake Engineering \& Structural Dynamics, Vol. 38, No. 7, pp. 887-905. 
Kwon, O.S. and Elnashai, A. (2006). "The Effect of Material and Ground Motion Uncertainty on the Seismic Vulnerability Curves of RC Structure", Engineering Structures, Vol. 28, No. 2, pp. 289-303.

Kwon, O.S. and Elnashai, A. (2007) "Fragility Analysis of a Bridge with Consideration of Soil-Structure-Interaction Using Multi-Platform Analysis", Structural Engineering Research Frontiers, John W. Wallace, ed., Long Beach, California, USA, May, pp. 1-14. Lee, K.H. and Rosowsky, D.V. (2006). "Fragility Analysis of Woodframe Buildings Considering Combined Snow and Earthquake Loading", Structural Safety, Vol. 28, No. 3, pp. 289-303.

Lee, L.H., Lee, H.H. and Han, S.W. (2000). "Method of Selecting Design Earthquake Ground Motions for Tall Buildings", The Structural Design of Tall Buildings, Vol. 9, No. 3, pp. 201-213.

Lee, S.H. and Chen, W. (2009). "A Comparative Study of Uncertainty Propagation Methods for Black-Box-Type Problems", Structural and Multidisciplinary Optimization, Vol. 37, No. 3, pp. 239-253.

Li, Y. and Ellingwood, B.R. (2009). "Framework for Multihazard Risk Assessment and Mitigation for Wood-Frame Residential Construction", Journal of Structural Engineering, Vol. 135, No. 2, pp. 159-168.

Liel, A.B., Haselton, C.B., Deierlein, G.G. and Baker, J.W. (2009). "Incorporating Modeling Uncertainties in the Assessment of Seismic Collapse Risk of Buildings", Structural Safety, Vol. 31, No. 2, pp. 197-211.

Lin, S.L., Li, J., Elnashai, A.S. and Spencer Jr, B.F. (2012). "Nees Integrated Seismic Risk Assessment Framework (Nisraf)", Soil Dynamics and Earthquake Engineering, Vol. 42, pp. 219-228. 
Luco, N. (2002). Probabilistic Seismic Demand Analysis, Smrf Connection Fractures, and near-Source Effects, PhD Thesis, Stanford University, CA, USA.

Luco, N., Bazzurro, P. and Cornell, C.A. (2004) "Dynamic Versus Static Computation of the Residual Capacity of a Mainshock-Damaged Building to Withstand an Aftershock", Proceedings of the 13th World Conference on Earthquake Engineering, Vancouver, British Columbia, Canada.

Luco, N. and Cornell, C.A. (2000). "Effects of Connection Fractures on Smrf Seismic Drift Demands", Journal of Structural Engineering, Vol. 126, No. 1, pp. 127-136.

Luco, N. and Cornell, C.A. (2007). "Structure-Specific Scalar Intensity Measures for nearSource and Ordinary Earthquake Ground Motions", Earthquake Spectra, Vol. 23, No. 2, pp. 357-392.

Mahin, S., Malley, J. and Hamburger, R. (2002). "Overview of the FEMA/SAC Program for Reduction of Earthquake Hazards in Steel Moment Frame Structures", Journal of Constructional Steel Research, Vol. 58, No. 5-8, pp. 511-528.

Mander, J.B. and Rodgers, G.W. (2013) "Cyclic Fatigue Demands on Structures Subjected to the 2010-2011canterbury Earthquake Sequence", NZSEE Technical Conference and AGM, Wellington, New Zealand.

Matthies, H.G. (2007). "Quantifying Uncertainty: Modern Computational Representation of Probability and Applications." In Extreme Man-Made and Natural Hazards in Dynamics of Structures, A. Ibrahimbegovic and I. Kozar, ed., pp. 105-135.

McGuire, R.K. (2008). "Probabilistic Seismic Hazard Analysis: Early History", Earthquake Engineering \& Structural Dynamics, Vol. 37, No. 3, pp. 329-338.

Mehani, Y., Bechtoula, H., Kibboua, A. and Naili, M. (2013). "Damage Quantification of Steel Moment Resisting Frames Using Ductility Parameters", KSCE Journal of Civil Engineering, Vol. 17, No. 6, pp. 1394-1402. 
Montiel, M.A. and Ruiz, S.E. (2007). "Influence of Structural Capacity Uncertainty on Seismic Reliability of Buildings under Narrow-Band Motions", Earthquake Engineering \& Structural Dynamics, Vol. 36, No. 13, pp. 1915-1934.

Mosleh, A. and Apostolakis, G. (1986). "The Assessment of Probability Distributions from Expert Opinions with an Application to Seismic Fragility Curves", Risk Analysis, Vol. 6, No. 4, pp. 447-461.

Mottershead, J.E. and Friswell, M.I. (1993). "Model Updating in Structural Dynamics: A Survey", Journal of sound and vibration, Vol. 167, No. 2, pp. 347-375.

Nielson, B.G. and DesRoches, R. (2007). "Seismic Fragility Methodology for Highway Bridges Using a Component Level Approach", Earthquake Engineering \& Structural Dynamics, Vol. 36, No. 6, pp. 823-839.

Padgett, J.E. and DesRoches, R. (2007). "Sensitivity of Seismic Response and Fragility to Parameter Uncertainty", Journal of Structural Engineering, Vol. 133, No. 12, pp. 17101718.

Padgett, J.E., Ghosh, J. and Dueñas-Osorio, L. (2010). "Effects of Liquefiable Soil and Bridge Modelling Parameters on the Seismic Reliability of Critical Structural Components", Structure and Infrastructure Engineering, pp. 1-19.

Padgett, J.E., Nielson, B.G. and DesRoches, R. (2008). "Selection of Optimal Intensity Measures in Probabilistic Seismic Demand Models of Highway Bridge Portfolios", Earthquake Engineering \& Structural Dynamics, Vol. 37, No. 5, pp. 711-725.

Paret, T.F., Searer, G.R. and Freeman, S.A. (2011) "ASCE 31 and 41: Apocalypse Now", Proceedings of the 2011 Structures Congress, D. Ames, T. L. Droessler and M. Hoit, ed., Las Vegas, Nevada, USA, April, pp. 2741-2755.

Park, Y.J. and Ang, A.H.S. (1985). "Mechanistic Seismic Damage Model for ReinforcedConcrete", Journal of Structural Engineering, Vol. 111, No. 4, pp. 722-739. 
Paté-Cornell, M.E. (1996). "Uncertainties in Risk Analysis: Six Levels of Treatment", Reliability Engineering \& System Safety, Vol. 54, No. 2-3, pp. 95-111.

Porter, K. , A.S., Kiremidjian and LeGrue, J.S. (2001). "Assembly-Based Vulnerability of Buildings and Its Use in Performance Evaluation", Earthquake Spectra, Vol. 17, No. 2, pp. 291-312.

Porter, K., Kennedy, R.P. and Bachman, R. (2007). "Creating Fragility Functions for Performance-Based Earthquake Engineering", Earthquake Spectra, Vol. 23, No. 2, pp. 471-489.

Raghunandan, M. and Liel, A.B. (2013). "Effect of Ground Motion Duration on EarthquakeInduced Structural Collapse", Structural Safety, Vol. 41, pp. 119-133.

Réveillère, A., Gehl, P., Seyedi, D. and Modaressi, H. (2012) "Development of Seismic Fragility Curves for Mainshock-Damaged Reinforced-Concrete Structures", Proceedings of the 15th World Conference on Earthquake Engineering, Lisbon, Portugal.

Reyes, J.C. and Kalkan, E. (2012). "How Many Records Should Be Used in an ASCE/SEI-7 Ground Motion Scaling Procedure?", Earthquake Spectra, Vol. 28, No. 3, pp. 1223-1242.

Romão, X., Delgado, R. and Costa, A. (2013). "Alternative Closed-Form Solutions for the Mean Rate of Exceedance of Structural Limit States", Earthquake Engineering \& Structural Dynamics, Vol. 42, No. 12, pp. 1827-1845.

Rossetto, T. and Elnashai, A. (2003). "Derivation of Vulnerability Functions for EuropeanType RC Structures Based on Observational Data", Engineering Structures, Vol. 25, No. 10, pp. 1241-1263.

Ruiz-García, J. and Miranda, E. (2010). "Probabilistic Estimation of Residual Drift Demands for Seismic Assessment of Multi-Story Framed Buildings", Engineering Structures, Vol. 32, No. 1, pp. 11-20. 
Searer, G.R., Paret, T.F. and Freeman, S.A. (2008) "ASCE-31 and ASCE -41: What Good Are They?", ASCE Structures Congress, Vancouver, Canada, D. Anderson, C. Ventura, D. Harvey and M. Hoit, ed., Vancouver, British Columbia, Canada, April, pp. 1-8.

Seo, J. and Linzell, D.G. (2013). "Use of Response Surface Metamodels to Generate System Level Fragilities for Existing Curved Steel Bridges", Engineering Structures, Vol. 52, No. 1, pp. 642-653.

Shinozuka, M., Feng, M.Q., Lee, J. and Naganuma, T. (2000). "Statistical Analysis of Fragility Curves", Journal of Engineering Mechanics, Vol. 126, No. 12, pp. 1224-1231.

Shome, N. (1999). Probabilistic Seismic Demand Analysis of Nonlinear Structures, PhD Thesis, Stanford University, CA, USA.

Shome, N., Cornell, C. A., Bazzurro, P. and Carballo, J. E. (1998). "Earthquakes, Records, and Nonlinear Responses", Earthquake Spectra, Vol. 14, No. 3, pp. 469-500.

Singhal, A. and Kiremidjian, A.S. (1998). "Bayesian Updating of Fragilities with Application to RC Frames", Journal of Structural Engineering, Vol. 124, No. 8, pp. 922-929.

Singhal, A. and Kiremidjian, A.S. (1996). "Method for Probabilistic Evaluation of Seismic Structural Damage", Journal of Structural Engineering, Vol. 122, No. 12, pp. 1459-1467.

Somja, H., Nofal, S., Hjiaj, M. and Degee, H. (2013). "Effect of the Steel Material Variability on the Seismic Capacity Design of Steel-Concrete Composite Structures: A Parametric Study", Bulletin of Earthquake Engineering, Vol. 11, No. 4, pp. 1099-1127.

Song, J. and Kang, W.H. (2009). "System Reliability and Sensitivity under Statistical Dependence by Matrix-Based System Reliability Method", Structural Safety, Vol. 31, No. 2, pp. 148-156.

Song, J. and Kiureghian, A.D. (2003). "Bounds on System Reliability by Linear Programming", Journal of Engineering Mechanics, Vol. 129, No. 6, pp. 627-636. 
Stander, N. and Craig, K.J. (2002). "On the Robustness of a Simple Domain Reduction Scheme for Simulation-Based Optimization", Engineering Computations, Vol. 19, No. 34, pp. 431-450.

Teran-Gilmore, A. and Jirsa, J.O. (2007). "Energy Demands for Seismic Design against LowCycle Fatigue", Earthquake Engineering \& Structural Dynamics, Vol. 36, No. 3, pp. 383404.

Tesfamariam, S. and Sadiq, R. (2006). "Probabilistic Risk Analysis Using Ordered Weighted Averaging (Owa) Operators", Stochastic Environmental Research and Risk Assessment, Vol. 22, No. 1, pp. 1-15.

Towashiraporn, P. (2004). Building Seismic Fragilities Using Response Surface Metamodels, PhD Thesis, Georgia Institute of Technology, GA, USA.

Tso, W.K., Zhu, T.J. and Heidebrecht, A.C. (1992). "Engineering Implication of Ground Motion a/V Ratio", Soil Dynamics and Earthquake Engineering, Vol. 11, No. 3, pp. 133144.

Vamvatsikos, D. (2013). "Derivation of New SAC/FEMA Performance Evaluation Solutions with Second-Order Hazard Approximation", Earthquake Engineering \& Structural Dynamics, Vol. 42, No. 8, pp. 1171-1188.

Vamvatsikos, D. and Cornell, C.A. (2002). "Incremental Dynamic Analysis", Earthquake Engineering \& Structural Dynamics, Vol. 31, No. 3, pp. 491-514.

Vamvatsikos, D. and Dolsek, M. (2011). "Equivalent Constant Rates for Performance-Based Seismic Assessment of Ageing Structures", Structural Safety, Vol. 33, No. 1, pp. 8-18.

Vamvatsikos, D. and Fragiadakis, M. (2010). "Incremental Dynamic Analysis for Estimating Seismic Performance Sensitivity and Uncertainty", Earthquake Engineering \& Structural Dynamics, Vol. 39, No. 2, pp. 141-163. 
Wang, Z., Dueñas-Osorio, L. and Padgett, J.E. (2013). "Seismic Response of a Bridge-SoilFoundation System under the Combined Effect of Vertical and Horizontal Ground Motions", Earthquake Engineering \& Structural Dynamics, Vol. 42, No. 4, pp. 545-564.

Ye, L., Ma, Q., Miao, Z., Guan, H. and Zhuge, Y. (2013). "Numerical and Comparative Study of Earthquake Intensity Indices in Seismic Analysis", The Structural Design of Tall and Special Buildings, Vol. 22, No. 4, pp. 362-381.

Yeo, G.L. and Cornell, C.A. (2009). "Equivalent Constant Rates for Post-Quake Seismic Decision Making", Structural Safety, Vol. 31, No. 5, pp. 443-447.

Yun, S.Y., Hamburger, R.O., Cornell, C.A. and Foutch, D.A. (2002). "Seismic Performance Evaluation for Steel Moment Frames", Journal of Structural Engineering, Vol. 128, No. 4, pp. 534-545.

Zareian, F. and Krawinkler, H. (2010). "Structural System Parameter Selection Based on Collapse Potential of Buildings in Earthquakes", Journal of Structural Engineering, Vol. 136, No. 8, pp. 933-943.

Zhang, J. and Huo, Y. (2009). "Evaluating Effectiveness and Optimum Design of Isolation Devices for Highway Bridges Using the Fragility Function Method", Engineering Structures, Vol. 31, No. 8, pp. 1648-1660.

Zhang, J., Huo, Y., Brandenberg, S.J. and Kashighandi, P. (2008). "Effects of Structural Characterizations on Fragility Functions of Bridges Subject to Seismic Shaking and Lateral Spreading", Earthquake Engineering and Engineering Vibration, Vol. 7, No. 4, pp. 369-382. 